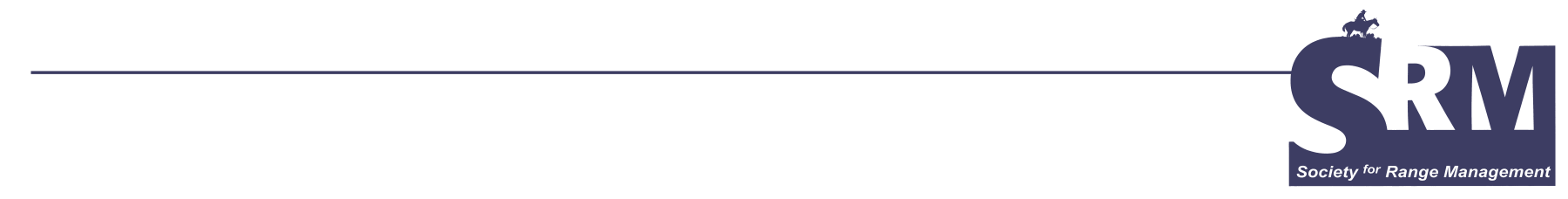

\title{
Games People Play
}

\section{Human Behavior and Invasive Weed Management}

\section{By Nicole Haynes McCoy and Pradyumna Amatya}

\section{Introduction}

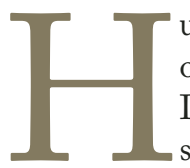

uman behavior has implications for the success of invasive weed management strategies. Invasive weeds are mobile; vegetative spread or multiple property boundaries.

Public education serves an important role in combating infestations. However, education does not necessarily result in weed control efforts; education is only one component of the decisions that people make to support or engage in weed control efforts. A landowner may understand that invasive weeds are undesirable, but such understanding may not translate into active control of an infestation. The control of invasive species is a "weakest link" public good-the benefits to everyone are determined by the efforts of the weakest. ${ }^{1}$

Students of invasive plant management learn the biology of weeds, their impacts on ecological and economic systems, to map and monitor noxious weeds, to develop and employ integrated strategies, and the efficacy of alternative technologies. Yet, education of weed professionals is often missing a critical factor: the effect of human behavior. If this behavior - its rationale and implications - are not well understood, the success of long-term, landscape-level weed management is reduced.

This article uses principles of economic game theory to illustrate a strategic weed control game, Weakest Link Weed Management (WLWM), intended for use in the classroom. Game theory is the science of rational behavior in interactive situations; use of this construct allows students to explore how their preferences and limitations affect their actions.

This game is a tool that teaches weed scientists and managers the decision situations that individuals, land managers, and social planners confront in developing and implementing invasive weed management strategies. By using a simple game of 2 players, we present an example of how perceptions of value influence weed control decision-making. The game is appropriate for adults, regardless of their knowledge of weed management and can be played by 2 or more players.

The game addresses the following implications of human behavior in weed management:

1. The impact of information asymmetry in weed control decisions.

2. The effect of external costs on potential payoffs.

3. The effectiveness of regulation.

4. The potential of negotiation.

\section{Game Framework}

When a landscape is threatened by an invasive plant infestation, each landowner on that landscape decides whether to pursue a weed management strategy on his or her property. The decision any landowner makes regarding whether or not to control an infestation depends on how that individual values the outcome of weed management when compared with the value generated by other activities. In any landowner's mind, the net value of the results of weed treatment efforts must be positive for a landowner even to consider treatment. Although this is a necessary condition, it is not sufficient to 
Table 1. Player handout containing neighborhood description, role descriptions, and scorecard

\section{Neighborhood Description}

A neighborhood consisting of 7,000 acres owned by 2 separate landowners is facing an infestation of an invasive exotic weed. Each landowner must determine how he or she will react to this infestation given his or her own interests and the behavior of the neighbor. Each landowner's well-being depends on the benefit he or she receives from treating the infestation as well as the benefit he or she receives from engaging in unrelated activities. This well-being is quantified in each landowner's payoff. Keep in mind that each landowner faces a budget constraint: dollars that are used for treating weeds cannot be used on other activities and vice versa.

\section{Landowner 1 Role Description}

You are a third generation rancher with a 5,000 acre cow-calf operation. Your livestock graze the ranch for several months of the year and you recognize that healthy, weed-free rangelands result in greater weight gain and healthier livestock. Lately, though, an invasive exotic weed has been encroaching onto your lands. This weed has low palatability and nutritional benefits, and you are concerned about the implications of this weed on the financial and biological health of your operation.

\section{Landowner 2 Role Description}

You are a real estate developer who has recently purchased 2,000 acres of rangeland as an investment property. The area that you have purchased is in close proximity to growing suburbs of a major metropolitan area, and you expect to start building subdivisions in this area in the next couple of years. You have some awareness that an invasive exotic weed is encroaching on the area, but this is of little concern to you as your land value is based upon developmental potential and not on ecological health; this exotic weed has no negative effect on the value of your property. You have an obligation to your investors to maximize the revenues you gain from your real estate transactions.

\begin{tabular}{|c|c|c|c|}
\hline \multicolumn{3}{|c|}{ Payoff Scorecard } & \multirow[t]{2}{*}{ Comments } \\
\hline & $\begin{array}{c}\text { Treatment? } \\
\text { Yes/No }\end{array}$ & Payoff & \\
\hline \multicolumn{4}{|c|}{ Round 1} \\
\hline \multicolumn{4}{|c|}{ Round 2} \\
\hline \multicolumn{4}{|c|}{ Round 3} \\
\hline \multicolumn{4}{|c|}{ Round 4} \\
\hline $\begin{array}{l}\text { Total } \\
\text { payoff }\end{array}$ & & & \\
\hline
\end{tabular}

guarantee that treatment will occur. If a landowner perceives his or her utility (well-being) to be greater by not controlling weeds, weed control will not occur.

As weed infestations are mobile, weed treatment decisions made on one property can affect the well-being of a neighboring property owner. If one landowner does not control his or her weeds, that can impose an additional cost on a neighboring property owner, whose lands are being reinfested from the nearby seed source. As a result, to maintain the same weed control benefits, more of the neighbor's budget must be allocated to weed control and less can go to other uses.

A person's wealth can be used to combat invasive weeds to generate or protect a value, or it can be allocated to purchase a breadth of other goods and services such as recreation, edu- cation, or groceries. If the price of weed control increases without a commensurate increase in value, less may be purchased.

In the WLWM game, 2 landowners occupy a landscape with an invasive weed problem. One landowner's utility is not affected by his or her neighbor. However, the other landowner's well-being is subject to the actions of the first property owner. The unaffected landowner has a dominant strategy not to treat the weeds; that strategy is costly to the neighbor.

The game was tested in 4 different courses (80 participants total) at Utah State University in the spring of 2005. Participants included undergraduates (freshmen through seniors), graduate students, and faculty. In general, under- 
graduate participants had a limited knowledge of invasive plants; graduate students and faculty possessed more comprehensive knowledge of invasive weed problems. Our inclass trials provide insight for what other educators may experience when conducting the game. This article presents an abbreviated version of the game instructions with classroom discussion. Complete instructions are available at http://www.cnr.usu.edu/faculty/nmccoy.

\section{WLWM Game Instructions}

There are 2 roles in this game: 1) Rancher and 2) Developer. The instructor pairs participants and assigns each the role of Rancher or Developer; some pairs should be made up of 2 ranchers or 2 developers, and some pairs should have one of each.

The instructor gives each participant the neighborhood description, both role descriptions, and a scorecard, as shown in Table 1. Each participant should be told that their partner may be either a rancher or a developer, but for the time being, each person should keep his or her identity and pay- off confidential. Each participant is provided the payoff scenario associated with their assigned role (Table 2). The payoff amounts selected are designed to provide incentives for participation while remaining affordable for the instructor.

\section{Game Play}

\section{Round 1: Information Asymmetry and} Dominant Strategy

As the round begins, participants are reminded that, in this game, their dollar payoff amount represents their overall wellbeing and that their objective is to maximize individual earnings. In this round, each partner's decision whether or not to treat their own infestation must be made simultaneously.

Participants record their first-round play (treatment or no treatment), and all players reveal their roles to their partners. Possible payoffs for all 3 pair-types are shown in the matrices of Table 3A-C (the developer's payoff is listed first, the rancher's is second); players can be shown these matrices after the first round. Participants should record their individual

Table 2. Player handout containing payoff scenarios; each player receives only the scenario that corresponds to his or her assigned role

\section{Landowner 1 (Rancher) Payoff Scenarios}

There are 4 possible scenarios that you may encounter:

1. Both you and your neighbor treat the infestation on your respective lands. For you, this is an ideal situation. You can get a handle on your own weed problem, and you won't be facing a reinfestation from your neighbor's lands. You can devote your budget to eradicating this infestation and then use the money you save from not having to treat the infestation over the ensuing years on other activities (eg, invest it in the stock market). As this is an ideal situation for you, you will enjoy the maximum payoff of $\$ 0.40$ under this scenario.

2. You treat your weeds, but your neighbor does not treat his or her weeds. This is a highly undesirable outcome for you. Because your neighbor fails to treat his or her weeds, no matter what you do, you face reinfestation from your neighbor's lands over the long term. As a result, the long-term costs of treatment exceed the long-term benefits. You will have spent money that could have been used in an alternative, and more productive, fashion (eg, invested in the stock market). Your payoff under this scenario will be $-\$ 0.10$.

3. You do not treat your weeds, but your neighbor does treat his or her weeds. Even if you do nothing, you will receive some benefit from your neighbor's actions because the infestation of the weed onto your property will slow as a result. You can use the money you don't spend on weed treatment to invest in the stock market or take the family to Disney World, even though your livestock productivity starts to fall because the weed infestation worsens. Your payoff under this scenario is $\$ 0.20$. 4. You do not treat your weeds, and your neighbor also does not treat his or her weeds. If you do not treat your weeds, you can still devote your entire budget to other activities. However, while your family is at Disney World or watching its stock portfolio grow, your rangeland is rapidly becoming infested, and your livestock productivity decreases quicker than in scenario \#3. As a result, your payoff will be $\$ 0.10$.

\section{Landowner 2 (Developer) Payoff Scenarios}

There are only 2 scenarios that you face:

1. You do not treat your weeds. Your payoff is not dependent on the actions of your neighbor; treating weeds involves a cost that would not be recouped when the land is developed. As a result you are indifferent to what your neighbor does with his or her own weeds. You plan on using your full budget to create realizable value for your investors: utility infrastructure, access, and marketing. If you do not treat your weeds, your payoff will be $\$ 0.40$.

2. You treat your weeds. If you treat your weeds, the outcome, according to the scenario defined above, will be undesirable. Your payoff can only be negatively affected by treating your weeds; for you, there is no benefit of weed treatment, and if you use your budget to combat the infestation, that is money that could have been otherwise used to add real value to your property (eg, utility infrastructure). If you treat your weeds, your payoff is $-\$ 0.10$. 
Table 3. Payoff matrix for rounds 1 and 2; the payoff for the row is listed first; the instructor pays each participant the amount he or she earns; negative payoffs mean a participant must pay the instructor

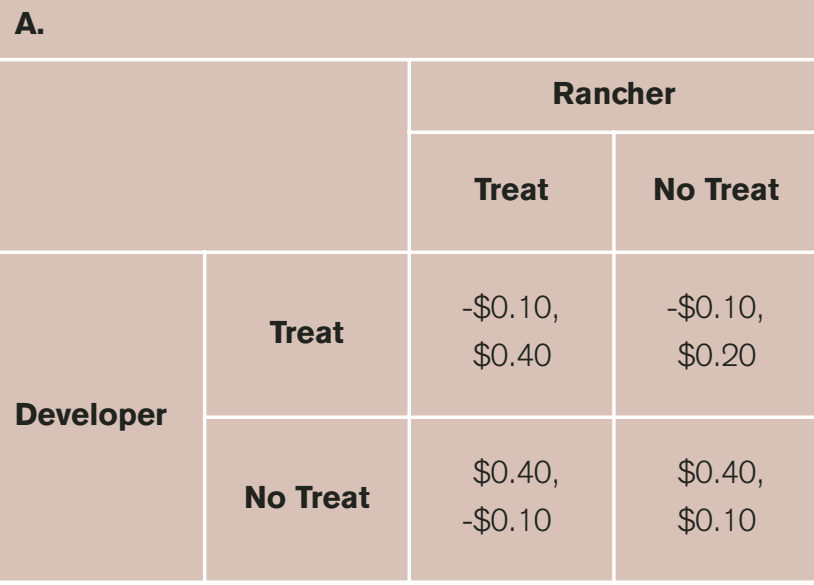

B.

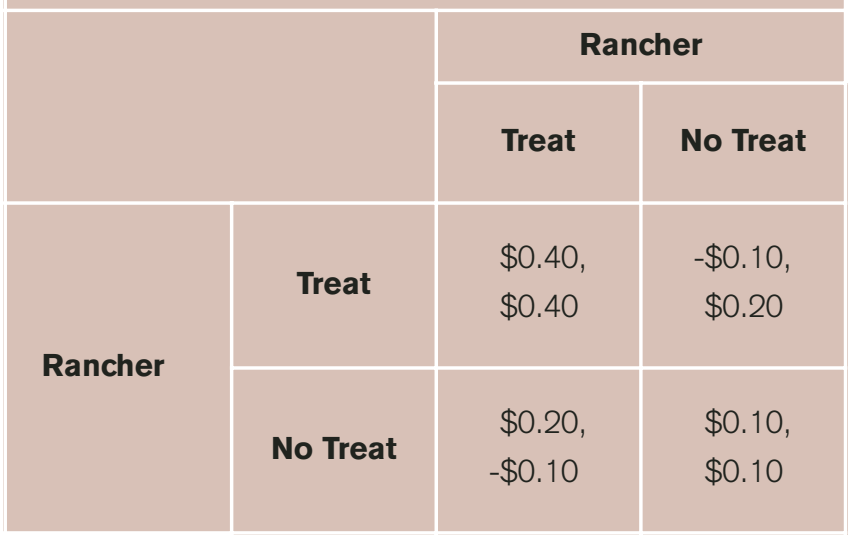

c.

\begin{tabular}{|c|c|c|c|}
\hline & & \multicolumn{2}{|c|}{ Developer } \\
\hline & & Treat & No Treat \\
\hline \multirow{2}{*}{ Developer } & Treat & $\begin{array}{l}-\$ 0.10 \\
-\$ 0.10\end{array}$ & $\begin{array}{c}-\$ 0.10 \\
\$ 0.40\end{array}$ \\
\hline & No Treat & $\begin{array}{l}\$ 0.40 \\
-\$ 0.10\end{array}$ & $\begin{array}{l}\$ 0.40 \\
\$ 0.40\end{array}$ \\
\hline
\end{tabular}

payoffs on their scorecards. There is no discussion between rounds 1 and 2 .

There are 2 sources of uncertainty present in round 1 : first, the role of the "neighbor," and second, the payoff a neighbor (and hence the player themselves) receives from alternative actions. This uncertainty leads to information asymmetry; one party knows more than the other. In this case, developers know that their payoffs are unaffected by the actions of their neighbors, and ranchers know that their payoffs are affected by their partners.

Developers have a distinct advantage in this round because they know how they will fare regardless of their partners' play. This illustrates the presence of a dominant strategy - a rational developer will always choose not to treat the weeds. Therefore, the outcome of the developer-developer pairs should result in both parties maximizing their payoffs.

In the rancher-developer pairing, the outcome should be in the bottom row of Table $3 \mathrm{~A}$, reflecting the no treatment option employed by the developer. The payoff for the rancher depends on whether or not he or she decided to treat. This illustrates a further information asymmetry: simultaneous decision-making ensures that the rancher does not possess all of the information that he or she needs to make a decision that will result in a positive payoff.

The rancher-rancher pairing illustrates what is known as a prisoner's dilemma problem. Both ranchers maximize their payoffs if they both treat their weeds. However, there is an element of uncertainty present in this problem because neither rancher knows whether his or her partner is a rancher. If ranchers suspect that their neighbors are developers, they may decide not to treat for fear of losing money.

\section{Round 2: Complete Information and External Costs}

Using the information learned from round 1, players again decide whether or not to treat; simultaneous decision-making is not necessary, but discussion between partners is not allowed.

The expected outcome of this round should be identical for the developer-developer pairing (each partner earns $\$ 0.40)$. In the absence of uncertainty, the rancher-rancher pairing should yield a result in which both players maximized their payoffs by treating their weeds. The rancher-developer pairing should have resulted in both parties deciding not to treat their weeds, with an outcome for the developer $(\$ 0.40)$ being greater than that for the rancher $(\$ 0.10)$.

\section{Discussion of Rounds 1 and 2}

This discussion period is used to explore the behaviors that were observed during the first 2 rounds. The instructor may raise the following questions:

- Is this game fair?

- What was the impact of information asymmetry on ranchers?

- Did player behaviors change from the first to the second round and why?

- Did any developers decide to treat their weeds in either round 1 or 2? What makes these developers "different" 
Table 4. Potential payoffs under regulation scenario; the new payoff amounts provide a strong incentive for both participants to treat their weeds

A.

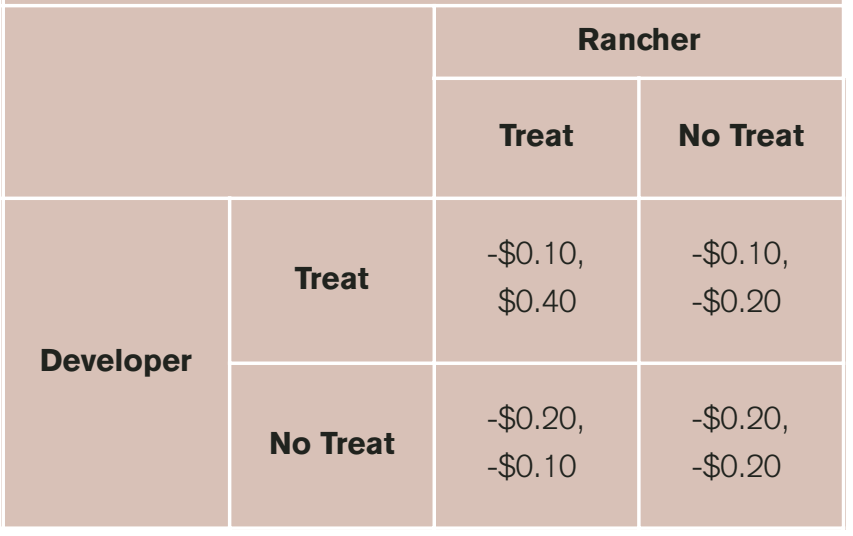

B.

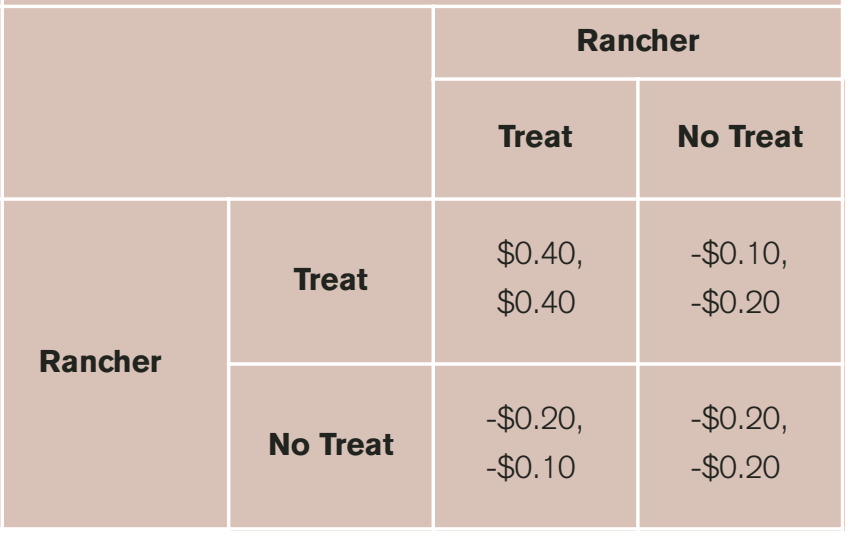

c.

\begin{tabular}{|c|c|c|c|}
\hline \multicolumn{2}{|c|}{} & \multicolumn{2}{c|}{ Developer } \\
\cline { 2 - 4 } & & Treat & No Treat \\
\hline & \multirow{2}{*}{ Treat } & $-\$ 0.10$, & $-\$ 0.10$, \\
& $-\$ 0.10$ & $-\$ 0.20$ \\
\hline \multirow{2}{*}{ Developer } & & $-\$ 0.20$, & $-\$ 0.20$, \\
& \multirow{2}{*}{ No Treat } & $-\$ 0.10$ & $-\$ 0.20$ \\
\hline
\end{tabular}

from the developer described in the role description?

- If the entire class represents the landscape vs just 2 landowners, what is the status of invasive weed management?
Participants may grumble that the game is not fair. Information asymmetry dictates that one participant knows more than the other and, therefore, has a better likelihood of achieving an optimal outcome. The instructor may remind the students that the game is intended to simulate real-world situations, which are often "unfair."

Many ranchers will lose money in the first round. In our experiments, results from the first round showed that $85 \%$ of all ranchers treated their weeds. Asked why they risked a negative payoff that could result from their partner being a developer, many ranchers responded that they trusted that their neighbors would treat their weeds, regardless of their partners' role. Although both partners possessed both role descriptions, their ignorance of their partners' role and payoff matrix and the relatively small loss resulting from a suboptimal decision led an overwhelming majority to treat their weeds.

Once the pairs learned who their neighbors were, their behavior adjusted accordingly. In the second round, only $8.7 \%$ of ranchers in rancher-developer pairs elected to treat their weeds, whereas $100 \%$ of rancher-rancher pairs treated their weeds. Ranchers who treated their weeds and lost money stated that they believed that weeds were undesirable and were, therefore, treating weeds "on principle."

Nine percent of developers treated their weeds, earning a negative payoff. These developers maintained that they knew weeds were bad and that they believed their "true" payoff would be greater than what was specified by the game. In all cases, the rancher saw the developer's choice and responded accordingly, resulting in a $(-\$ 0.10$ and $\$ 0.40)$ payoff for the developer and rancher, respectively.

Participants may raise the issue that, in the real world, invasive weed infestations would not stop at the boundaries of a 7,000-acre landscape. The instructor should ask the students what would happen if their entire class represented the landscape at risk of invasion. If the game was changed so that any landowner's payoff would be negative if just one other landowner failed to treat his or her invasive plants, it would provide a strong disincentive for anyone to manage his or her weeds.

Successful landscape-level weed treatment programs must acknowledge that payoffs are critical in decision-making. The payoff from not treating weeds must be less than the payoff earned from weed management. One way this can be achieved is to enact a penalty for not treating weeds, thereby reducing the no-treatment payoff.

Before the next round, the students and instructor should create a new matrix that reflects the lowered payoffs resulting from noncompliance and in which the equilibrium outcome has both parties treating their weeds. The amount of the penalty doesn't matter, as long as the dominant strategy for both parties is to treat their weeds. Table 4 shows an option in which a penalty for not treating weeds reduces both payoffs to $-\$ 0.20$. 
Table 5. Potential outcomes from negotiation: (A) shows an outcome where the rancher treats the developer's weeds at no cost to the developer but some cost to the rancher (row 1, column 1), and $(B)$ shows an outcome where the developer compensates the rancher because he or she does not treat the weeds (row 1 , column 1 )

A.

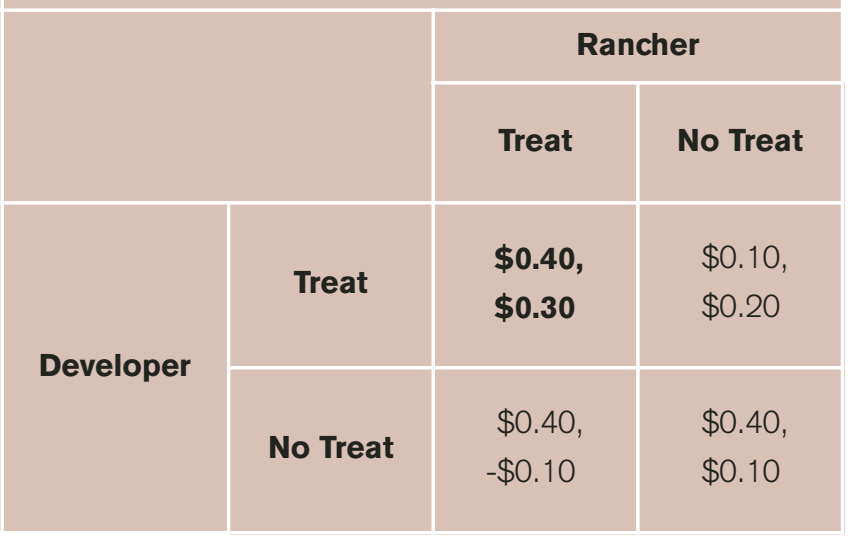

B.

\begin{tabular}{|c|c|c|c|}
\hline & & \multicolumn{2}{|c|}{ Rancher } \\
\hline & & Treat & No Treat \\
\hline \multirow{2}{*}{ Developer } & Treat & $\begin{array}{l}\$ 0.00 \\
\$ 0.40\end{array}$ & $\begin{array}{l}\$ 0.00 \\
\$ 0.20\end{array}$ \\
\hline & No Treat & $\begin{array}{l}\$ 0.30 \\
\$ 0.30\end{array}$ & $\begin{array}{l}\$ 0.30 \\
\$ 0.20\end{array}$ \\
\hline
\end{tabular}

\section{Round 3: Regulation}

Using the new payoff matrix, the pairs should play a third round. The expected result is that all treat their weeds. The ranchers earn $\$ 0.40$ and the developers lose $\$ 0.10$, which is less than what they would have to pay if they did not treat their weeds.

\section{Classroom Discussion of Round 3}

Although regulation has achieved a desirable outcome in which invasive weeds are now treated, the instructor will likely hear grumbling from half of the class. Whereas ranchers continue to earn money, the developers lose money.

Developers may be frustrated with an outcome that costs them. This is an ideal place for the instructor to introduce the effectiveness of regulation. A significant problem on many rangelands is that their size and scope prevents regulatory authorities from effective enforcement. If individuals don't believe enforcement will be carried out, they are unlike- ly to continue with an activity that is perceived as resulting in a negative payoff.

\section{Round 4: Negotiation}

For the last round of the game, all participants should be organized into developer-rancher pairs. They are told that there is no regulatory authority available to enforce weed treatment efforts. However, the pairs are free to discuss their respective situations and negotiate an outcome. Two possible outcomes include: 1 ) ranchers agree to treat developers' lands in addition to their own, and 2) developers don't treat their lands but compensate ranchers for losses or increased treatment costs.

Although it is not cost-effective for ranchers to treat their lands if developers do nothing and allow their weeds to spread, it may be cost-effective for ranchers to offer to treat the developers' lands. The payoff for the ranchers under this scenario is somewhat less than if the developers treat their own lands, but it is more than if the ranchers treat their lands but the developers do not. As long as a rancher's payoff is greater than or equal to $\$ 0.20$, the new solution will be optimal for both players. Developers maintain their payoffs $(\$ 0.40)$ because they are indifferent to whether or not their weeds are treated. One suggested payoff matrix is shown in Table 5A.

In the second scenario, the developer recognizes that by allowing weeds to spread onto his or her neighbor's property, an external cost is being created. Although the developer does not suffer the financial implications of this cost, he or she may be concerned about the social cost of his or her behavior. The rancher and the developer are able to agree that the developer will pay the rancher a sum that compensates the rancher for the external cost (Table 5B). The rancher is free to use that sum to combat the ongoing weed problem, or he or she may decide to invest the sum in another endeavor.

\section{Discussion of Round 4}

In all of our classroom trials, students were able to negotiate an outcome that was desirable for both neighbors. Although most of the outcomes from our trials followed the model of those presented above, a couple of interesting variations arose in one of the graduate classes. In one pair, the rancher agreed to treat the developer's weeds if the developer gave the rancher access to his forage while the land remained undeveloped. This allowed the rancher to recoup the costs of treating the developer's land. In another pair, the rancher threatened the developer into treating his own weeds. The rancher, knowing that the developer wished to create a subdivision in the area, stated that she would start a pig farm on her ranchland if the developer did not comply. The developer realized that his payoff from not treating his weeds would be reduced significantly in the presence of a pig farm and, therefore, agreed to treat his weeds.

It is useful to ask the participants how they were able to negotiate a desirable outcome. Many cite the fact that "they know each other." People who play this game have often spent 
days or even weeks getting to know each other inside a classroom. This may create an implied social contract. Students who are in close proximity, in either space or time, may suffer social ramifications of not "getting along" with each other.

In classes where this game is conducted, participants may be aware of, and concerned with, invasive exotic plants. As a result, any student whose role is a developer will have a greater understanding of, and education about, the invasive weed problem than the "developer" character they were assigned. The combination of education and a social contract can change a developer's internal payoff structure, even when he or she is ostensibly losing money.

Some participants may be more likely to negotiate because the payoff losses from negotiation are relatively small. A developer or rancher who gives up one dime loses very little compared with the loss of thousands of dollars or a livelihood. As the stakes of the game increase, negotiations become more complex. Nevertheless, as people have more to lose, they may be more willing to seek mutually beneficial ways to address the problem.

Cases may arise in which a negotiated outcome does not occur. In fact, this result happens quite often in the "real world." This is the heart of the social problem in weed management. In a patchwork landscape comprised of landowners who don't all know one another, who may or may not be present in the landscape, who face different incentives in a climate of ineffective regulation, it is almost inevitable that weed infestations will be undertreated.

\section{Discussion}

Ultimately, the invasive weed problem is a human predicament. For some landowners, invasive weeds may not be undesirable. This attitude may arise from a lack of education (if it is green it must be good), but, just as important, the belief may be real. In the WLWM game, the value of the developer's investment was unaffected by the presence of an invasive plant. This raises the question of why invasive weeds are considered "bad." Invasive weed infestations result in many negative ecological consequences. Yet, these consequences are only undesirable if our well-being is reduced by these implications. For the developer, that was not the case.
Regulation is one means of internalizing the external cost of invasive weed spread. Most states have regulations requiring landowners to treat noxious weeds, and if weeds are not treated, landowners can be either fined or billed for weed control conducted on their behalf. The United States has over 1.8 billion acres of rangeland in both public and private tenure; enforcement of regulations on that large of an acreage is next to impossible.

The value of weed treatment efforts is not limited to how the land is being used (eg, ranching vs development). The value a landowner places on weed treatment efforts may be impacted by how he or she is perceived by neighbors. Landowners who have close community ties may be more inclined to engage in weed treatment efforts, even when they perceive the direct value to be low because the social value of engaging in activities that benefit (or, at least, do not harm) the neighbors may be significant.

Negotiation can be an effective means of internalizing externalities if landowners are willing to come to the table. As the number of landowners in a landscape increases, negotiated outcomes become more and more difficult. Nevertheless, they are possible. In a recent study, we found that voluntary coalitions comprised of public and private landowners and private citizens were effective in managing invasive plant infestations in the southwest United States.

The WLWM allows weed managers to experience and discuss the complexity of human behavior and its implications for invasive plant management. After all, ultimately, the efforts of these landowners collectively influence the severity and outcome of invasive plant infestations.

Authors are Assistant Professor (McCoy) and PhD candidate (Amatya), Department of Environment and Society, 5215 Old Main Hill, Utah State University, Logan, UT 84322.

\section{References}

1. Perrings, C., M. Williamson, E. B. Barbier, D. Delfino, S. Dalmazzone, J. Shogren, P. Simmons, And A. WATKINSON. 2002. Biological invasion risks and the public good: an economic perspective. Conservation Ecology 6(1):1-7. 